\title{
Afe Adogame, James V. Spickard (éd.), Religion Crossing Boundaries. Transnational Religious and Social Dynamics in Africa and the New African Diaspora
}

Leiden-Boston, Brill, coll. «Religion and the Social Order», 18, 2010, $280 \mathrm{p}$.

\section{Baptiste Coulmont}

\section{OpenEdition \\ Journals}

Édition électronique

URL : http://journals.openedition.org/assr/23411

DOI : $10.4000 /$ assr.23411

ISSN : $1777-5825$

Éditeur

Éditions de l'EHESS

Édition imprimée

Date de publication : 31 décembre 2011

Pagination : 88

ISBN : 9782713223273

ISSN : 0335-5985

\section{Référence électronique}

Baptiste Coulmont, «Afe Adogame, James V. Spickard (éd.), Religion Crossing Boundaries.

Transnational Religious and Social Dynamics in Africa and the New African Diaspora », Archives de sciences sociales des religions [En ligne], 156 | octobre-décembre 2011, document 156-3, mis en ligne le 14 février 2012, consulté le 21 septembre 2020. URL : http://journals.openedition.org/assr/23411 ; DOI : https://doi.org/10.4000/assr.23411

Ce document a été généré automatiquement le 21 septembre 2020.

(c) Archives de sciences sociales des religions 


\section{Afe Adogame, James V. Spickard (éd.), Religion Crossing Boundaries. Transnational Religious and Social Dynamics in Africa and the New African Diaspora}

Leiden-Boston, Brill, coll. «Religion and the Social Order», 18, 2010, $280 \mathrm{p}$.

\section{Baptiste Coulmont}

\section{RÉFÉRENCE}

Afe Adogame, James V. SPICKARD (éd.), Religion Crossing Boundaries. Transnational Religious and Social Dynamics in Africa and the New African Diaspora, Leiden-Boston, Brill, coll. «Religion and the Social Order», 18, 2010, 280 p.

1 Les douze chapitres qui composent cet ouvrage collectif s'intéressent aux formes variées de circulation des croyants et des leaders d'Églises africaines (trouvant leur origine en Afrique, ou composées d'un public africain immigré ou émigré...). La grande majorité des exemples empiriques porte sur des groupes situés dans une mouvance évangélique ou pentecôtiste. Deux circulations sont privilégiées dans les études: les migrations vers le monde occidental (première partie) et les circulations «sud-sud» (seconde partie, principalement entre pays africains).

2 La diffusion africaine du pentecôtisme (qui déjà a fait l'objet d'une série de travaux) est ici abordée sous l'angle circulatoire plus que sous celui de l'implantation locale. Une introduction bienvenue (Spickard, Adogame, p.1-30) vient préciser ce qui est entendu sous le terme souvent flou de "transnational», qui apparaît autant lié à des évolutions sociales et techniques - l'augmentation du nombre de personnes circulant sur de 
longues distances - qu'à un changement du regard des sciences sociales - s'intéressant aux connexions que ces personnes gardent avec les lieux dans lesquels elles ont, auparavant, résidé, et concevant la migration comme une liaison d'espaces plutôt que comme rupture. L'ouvrage cherche alors à comprendre à la fois le rôle de la religion dans ces circulations transnationales et à mieux saisir ces circulations transnationales quand elles sont le fait d'Africains pentecôtistes ou appartenant à des Églises africaines charismatiques.

3 Ainsi, des études mentionnent les pratiques de partage de la chaire (pulpit sharing), d'échanges de bons procédés entre pasteurs (Parsito et Mwaura), ou se penchent sur le succès local, dans un pays africain, d'un pasteur occidental (Anugwom, au sujet de l'Allemand Bonnke).

4 Mais cette problématique apparente semble passer sous silence le rôle crucial de l'Étatnation, comme ensemble d'institutions contrai-gnantes. La frontière, les papiers, les ambassades, les restrictions de circulations apparaissent, en effet, souvent lors de la lecture des douze études. Mossière souligne que le chef pasteur d'une église de Kinshasa n'a jamais pu se rendre dans l'église de Montréal que dirige un de ses disciples. Le premier chapitre (Obadare, Adebanwi) étudie l'instrumentalisation magique de la religion dans le but d'obtenir des visas (par exemple, en amenant son passeport pour le faire bénir). L'étude d'Asamoah-Gyadu sur le rôle de la radio et du téléphone montre que les requêtes de prières pour les «papiers» arrivent en tête, avec les demandes de guérison. Krinsky (chap.11) souligne que les formes de circulation transnationales apparaissent conjointes avec le «renforcement» (p.233) de la nation postcoloniale en Afrique, comme forme d'identification. Plus généralement, la seconde partie de l'ouvrage, qui s'intéresse aux circulations religieuses «sud-sud» montre combien le rôle des frontières et celui des identités nationales importent. Noret souligne bien comment l'origine nationale permet - ou non - d'accéder à des réseaux transnationaux, sous une forme personnalisée ou bureaucratique et comment des réseaux cristallisent parfois des positions hiérarchiques (il existe une hiérarchie des connexions transnationales, p.115). Van de Kamp et Van Dijk étudient des mouvements au Mozambique et au Botswana en prenant, comme indicateur, «la position de l'Église par rapport à l'État-nation» (the faith's position toward the nation-state, p.124).

5 C'est donc le paradoxe de cet ouvrage, qui, tout en mettant en avant la fluidité et la multiplicité des identités transnationales postmodernes et postcoloniales, laisse voir la force persistante pour les acteurs comme pour la conceptualisation sociologique et anthropologique, de l'État, de la nation ou des frontières... autant d'institutions «modernes» incontournables. 